WHC-SP-0549

\title{
Independent Safety Evaluation of the Enriched Uranium Oxide Test UO-1
}

J. C. Van Keuren

Date Published

November 1989

Prepared for the U.S. Department of Energy Assistant Secretary for Nuclear Energy

(2) Westinghouse P.O. Box 1970

Richland, Washington 99352

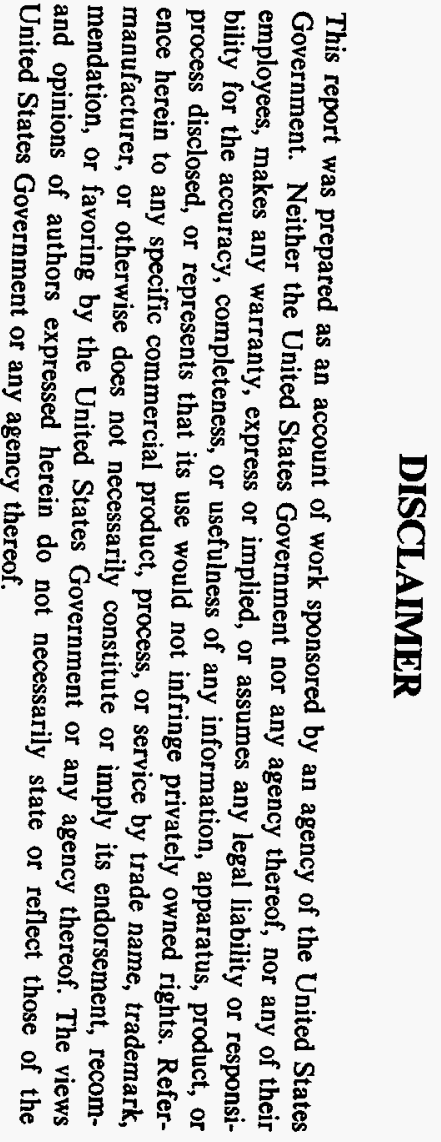

Hanford Operations and Engineering Contractor for the

U.S. Department of Energy under Contract DE-AC06-87RL10930 


\section{DISCLAIMER}

Portions of this document may be illegible in electronic image products. Images are produced from the best available original document. 


\section{CLASSIFICATION/UCNI REVIEW}

TO: Document Clearance/Processing and Distribution

SUBJECT: Review of WHC- $5 P-0549$

LC This document contains neither CLASSIFIED nor UCNI material.

This document is CLASSIFIED at the following level and category and may not be released:

Level
$\square$ Top Secret
$\square$ Secret
$\square$ Confidential

Category

Restricted Data

Formerly Restricted Data

National Security Information

This document contains UCNI material and any release must be in accordance with DOE appruved distribution lists.
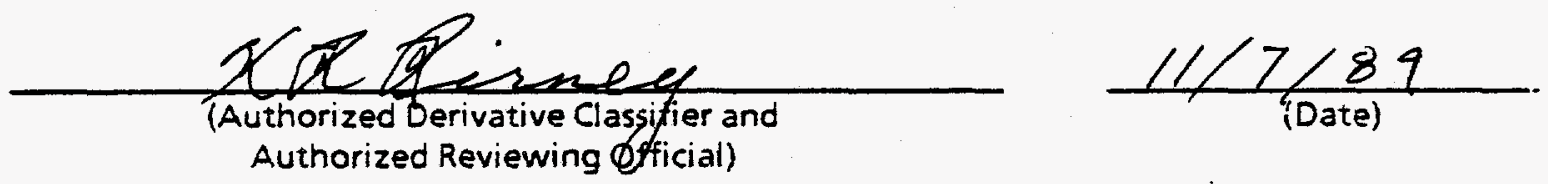

Please submit this completed form and document for distribution to:

Document Clearance/Processing and Distribution

L8-15 


\section{CONTENTS}

Page

1.0 Introduction ...................... 1

2.0 Summary and Conclusions ................. 1

3.0 Test Description .................... 2

4.0 Technical Specification Compliance .............. 5

5.0 Steady State Operation . . . . . . . . . . . . . 6

5.1 Experience with Similar Designs............ 6

5.2 Evaluation of the $\mathrm{UO}_{2}$ Pins .............. 6

5.3 S-4 Mixed Oxide Pin Evaluation . . . . . . . . . . . 7

5.4 Driver Fuel Pin Evaluation ............. 7

6.0 Transient Analyses ................... . . 13

7.0 Failure Consequences .................. 13

7.1 Consequences of a $\mathrm{Cl}$ adding Breach ........... 13

7.2 Misloading of Pins . . . . . . . . . . . . . . 14

7.3 Misloading of the Assembly into an Incorrect Core Location 14

8.0 HCDA Analyses .................... . . 14

9.0 Structural and Seismic Analyses . . . . . . . . . . . 14

10.0 Criticality and Test Handling Requirements . . . . . . . . 14

11.0 References .................... 15

\section{LIST OF FIGURES}

3-1 U0-1 Fuel Pin Loading Diagram ............... 4

5-1 Steady State Driver Fuel Pin Lifetime Criteria . . . . . . . 12

\section{LIST OF TABLES}

5-1 Experience with D9 Clad 0.230-Inch Diameter Oxide Fuel . . . 9

5-2 Steady State Analys is Assumptions . . . . . . . . . . . 10

5-3 Comparison of $\mathrm{UO}_{2}$ and Mixed 0xide Steady State Results . . . . 11 


\subsection{INTRODUCTION}

The U0-1 test is designed to provide information on the performance of D9 clad, enriched uranium oxide fuel in FFTF. The Series IV FFTF driver fuel will utilize enriched uranium oxide fuel with $D 9$ cladding. Irradiation data are needed for computer code calibration to support the FSAR analysis effort for the Series IV fuel. The U0-1 assembly consists of a 217-pin bundle with the same pin and duct dimensions as a standard driver fuel assembly. The test consists of seven $\mathrm{UO}_{2}$ pins, 30 mixed oxide test pins, and 180 driver type pins. The test will be irradiated for approximately 250 EFPD. Further details of the test design are given in Section 3.

An Independent Safety Evaluation (ISE) of the test has been conducted. Information has been taken from the Test Design Documents, 1,2 but independent calculations have been made of the safety-related parameters. The scope includes all items specified in the Users' Guide for Irradiation of Experiments in the FTR. 3 Areas investigated include Technical Specification Compliance, Steady State Operation, Transient Operation, Failure Consequences, Stress and Seismic, HCDA, and Test Handling and Criticality Considerations.

\subsection{SUMMARY AND CONCLUSIONS}

The results of this Independent Safety Evaluation (ISE) support irradiation of the U0-1 test.

The following limitations apply to the U0-1 test:

1. The irradiation exposure shal1 be limited to 270 EFPD.

2. The following peak linear power-to-flow limits apply:

Pin Type

$\mathrm{UO}_{2}$

S-4

\section{Peak Linear Power-to-Flow} at 0 EFPD $\left(10^{-5} \mathrm{~kW} / \mathrm{ft} / 1 \mathrm{~b} / \mathrm{hr}\right)$
Peak Linear Power-to-Flow at 270 EFPD $\left(10^{-5} \mathrm{~kW} / \mathrm{ft} / \mathrm{lb} / \mathrm{hr}\right)$

Driver Pins 7.88 7.18 6.57 5.98

Linear interpolation may be used to obtain the power-to-flow limits at intermediate exposures.

Completion of the following action item is required:

The Test Design Description Volume II (TDD-II), Parts 1 and 2, must be reviewed and approved prior to insertion of the test into the reactor.

The results of this ISE are summarized as follows:

1. The test complies with all the FFTF Technical Specifications.

2. The test steady state operating conditions are satisfactory. Coolant, cladding and fuel temperatures are below any safety limits. Analyses 
indicate that a cladding breach is improbable. The test does not appear to have any adverse effect on the core.

3. The transient performance of the test is bounded by the analyses that have been performed for other tests.

4. The analyses of failure consequences show no failure modes that would result in damage to the reactor, or result in off-site doses.

5. The test stress and seismic analyses considerations are enveloped by the analyses performed for the reference driver assembly.

6. The test will not affect the HCDA consequences.

7. The test can be handled using standard operating procedures. A modification to the refueling technical specification limits is not required.

\subsection{TEST DESCRIPTION}

The U0-1 test is designed to obtain information on the performance of enriched uranium oxide fuel in FFTF. The FFTF Series IV driver fuel assemblies will utilize enriched oxide fuel, and data are needed to support the FSAR effort. The assembly is a 217-pin bundle with the same duct and bundle design as the reference driver fuel assemblies. The pin cladding outside diameter is 0.230 inch. There are three basic types of fuel pins in this test:

The first type of pin is the $\mathrm{UO}_{2}$ pin. There are seven enriched uranium oxide fuel pins in the U0-1 test. The uranium enrichment is $42.9 \%$ U235. The fuel pellets have a 0.054 -inch annular hole in the center. The annulus promotes fuel motion in a severe accident and is a safety enhancement. The $\mathrm{UO}_{2}$ pins are located near the center of the pin bundle as shown in Figure 3-1. The $\mathrm{UO}_{2}$ pins will operate at approximately $13.25 \mathrm{~kW} / \mathrm{ft}$ peak linear power at beginning of life. The cladding is D9, which is an alloy similar to 316 stainless steel, except that the 09 alloy has reduced radiation-induced swelling. Two types of D9 are used, D9-C1P, which has had extensive irradiation experience in tests in FFTF, and D9-I, which is an improved version of D9. There are four D9-C1P clad $\mathrm{UO}_{2}$ fuel pins and three $\mathrm{D} 9-\mathrm{I} \mathrm{clad} \mathrm{UO}_{2}$ fuel pins.

The second type of pins are mixed oxide test pins, referred to as S-4 pins. The enrichment is $29 \% \mathrm{Pu} /(\mathrm{Pu}+\mathrm{U})$, which is slightly higher than the reference oxide pins. The S-4 pins will operate at a peak 1inear power of approximately $10.7 \mathrm{~kW} / \mathrm{ft}$ at beginning of $1 \mathrm{ife}$. The cladding is also $\mathrm{D9}$. There are $30 \mathrm{~S}-4$ pins. The location of the S-4 pins are shown in Figure 3-1.

The remaining pins are driver fuel pins. There are 54 Type 4.1 pins and 126 Type 3.1 pins. The 3.1 pins were part of the pins originally fabricated as part of the vendor qualification program. The principal difference between these pins and the pins normally used in driver fuel assemblies is that the vendor qualification pins do not contain gas tag capsules or gas tags. The lack of gas tags could complicate failure location if a pin breach occurs, but it is not a safety problem. A waiver to the gas tag requirement was granted for this test. 4 The 54 Type 4.1 pins were selected from a group of 
residual production pins and contain a variety of gas tags. The peak driver fuel pin power in this test is approximately $9.7 \mathrm{~kW} / \mathrm{ft}$. The enrichment for the 4.1 pins is $29.4 \% \mathrm{Pu} /(\mathrm{Pu}+\mathrm{U})$ and the enrichment of the 3.1 pins is $27.4 \%$ $\mathrm{Pu} /(\mathrm{Pu}+\mathrm{U})$.

The test is designed to operate for approximately 250 EFPD in Row 4 (Core Position 2405). The sodium coolant flow through the test is $171,000 \mathrm{lb} / \mathrm{hr}$, which is about $15 \%$ less than that of a standard driver. The peak coolant temperature is predicted to be about $1130^{\circ} \mathrm{F}$, which is within the range of irradiation temperatures for other tests with $D 9$ and 316 stainless steel cladding. 
WHC-SP-0549

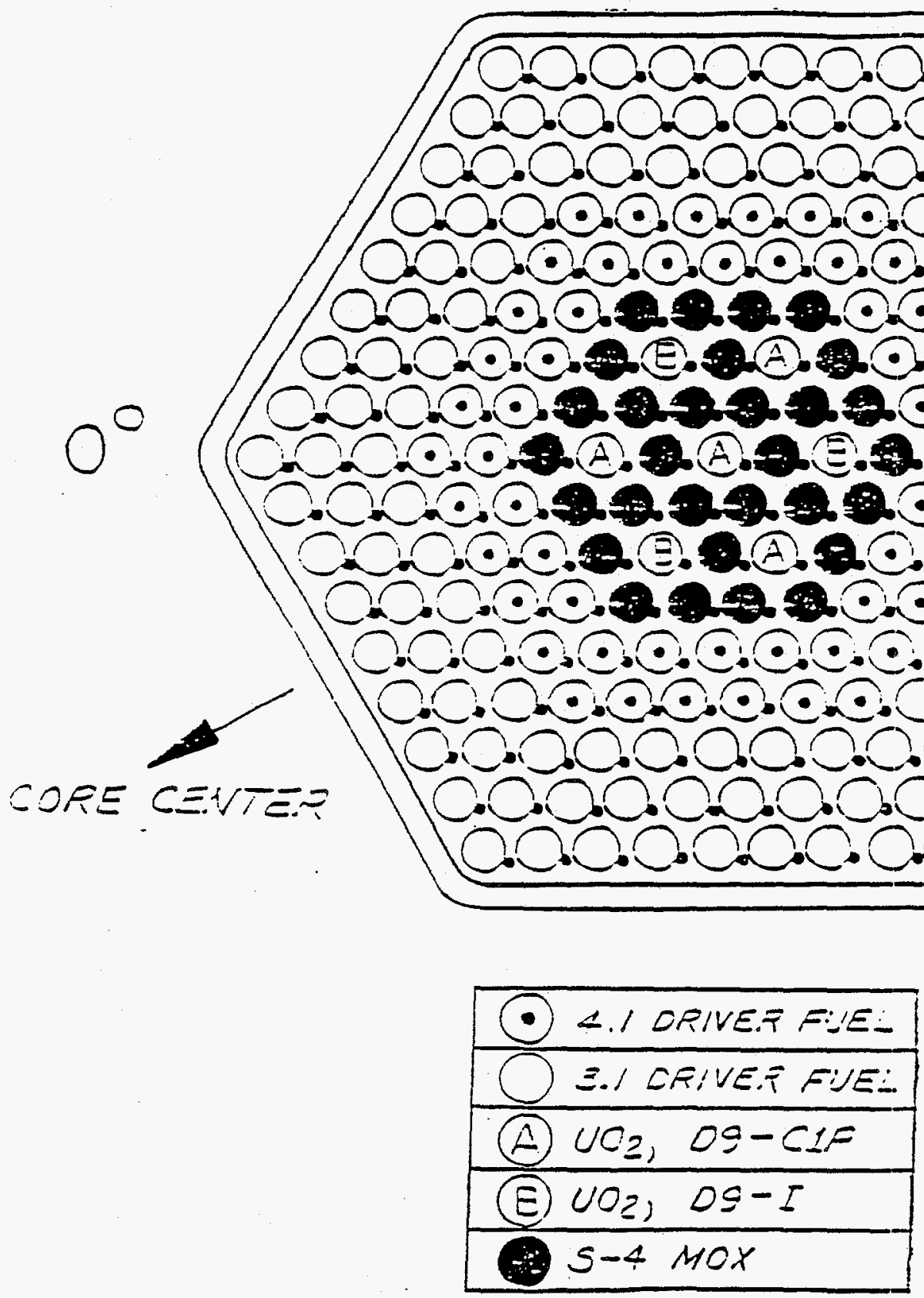

FIGURE 3-1. U0-1 Fuel Pin Loading Diagram 


\subsection{TECHNICAL SPECIFICATION COMPLIANCE}

The U0-1 test is to be irradiated in a Row 4 driver fuel location. Technical Specification 17.3.9.2 applies to tests irradiated in driver or reflector locations. Each provision of the specification is discussed below:

The reactor shall not be operated unless the following conditions are met:

a.1. The $210^{\circ} \mathrm{F}$ average temperature difference and the $270^{\circ} \mathrm{F}$ thermal striping limit of Technical Specification 17.3.1.2 shall be met.

Compliance with this specification depends on the core loading, and will be documented in the Reload Design Report (RDR). The outlet temperature for the U0-1 test is approximately the same as would be expected from a reference driver fuel assembly. Since a significant temperature difference is required for an assembly to exceed this specification limit, compliance is expected.

\section{a.2. The maximum reactivity worth of Technical Specification 17.3.1.1.d} shall be met.

This specification requires that the reactivity worth be less than $5.0 \$$. The U0-1 test has a slightly higher fissile content than the standard driver, but the difference is small. Compliance with this specification will be documented in the Reload Design Report (RDR) and the Reload Verification Report (RVR), but preliminary estimates indicate that compliance is expected.

b. Test assembly external geometry shall be compatible with adjacent assemblies and vessel internals throughout in-core residence and shall react core restraint loads without producing excessive stresses within the core system.

The test external geometry consists of the duct, load pads, inlet assembly and handling socket. These components all have the standard driver fuel assembly reference dimensions. The test will not produce excessive stresses. Radiation swelling or bowing will not be a factor, since the test exposure is limited to 250 EFPD. Radiation-induced swelling does not become significant until the fluence becomes much higher than the end-of-life fluence for this test. The test will therefore comply with this specification.

Technical Specification 17.3.9.4 also applies to this test.

The reactor shal1 not be operated with any EXPERIMENT that:

a. Would experience a loss of coolable geometry during any design transient.

b. Has a credible failure mode that would result in failure propagation beyond the assembly, or

c. Results in an increase in the severity of any transient beyond that documented in the FSAR.

The response of this test to design transients is discussed in Section 6 . The test performance is enveloped by analyses performed for other tests. coolant temperatures do not approach sodium boiling during any design 
WHC-SP-0549

transient, even at three sigma hot channel conditions. A limited amount of fuel melting may occur if a severe design transient would occur near beginning of life, but the amount would be very small, and cladding integrity will be maintained. Coolable geometry will therefore be maintained. Failure modes are discussed in Section 7 . There are no identified failure modes that would result in propagation beyond the assembly. The test will not affect reactor feedbacks or otherwise increase the severity of any design transients. The test therefore complies with this specification.

\subsection{STEADY STATE OPERATION}

This section describes the safety analysis of the steady state operation of the U0-1 test. Section 5.1 reviews the previous experience with tests with similar cladding and fuel designs. The performance of this test is compared to that of other tests which have successfully undergone irradiation. The subsequent sections report the steady-state operation evaluation for the different types of fuel pins in the test. Section 5.2 discusses the enriched $\mathrm{UO}_{2}$ pins, Section 5.3 reports the analysis of the S-4 pins, and Section 5.3 gives the results of the analysis of the driver fuel pins in the test.

\subsection{EXPERIENCE WITH SIMILAR DESIGNS}

The $\mathrm{UO}_{2}$ pins and the S-4 pins are the highest power pins in the assembly. These pins are clad with $D 9$ with a 0.230 -inch outside diameter. This section will give a review of the experience with similar fuel pin designs.

There have been a number of mixed oxide tests irradiated in FFTF with 09 cladding that have the same pin and duct dimensions as this test. (5-8) The test operating conditions that were assumed in the ISEs for these tests are summarized in Table 5-1, and are briefly discussed below. The D9-1 through -4 tests were irradiated to demonstrate the long lifetime capability of the D9 cladding and ducts. The tests were run to cladding breach and, as can be seen from Table 5-1, the tests reached quite high exposures. The CRBR-5 test was a Clinch River Breeder Reactor (CRBR) prototype fuel assembly utilizing D9. D9 was the lead candidate for the cladding and duct material for the advanced core design for CRBR. The C-1 test was a $D 9 \mathrm{cl}$ ad test designed to operate at two sigma hot channel conditions. All these tests completed irradiation without any indications of a safety problem. The tests that were run-to-cladding breach showed no indications of failure propagation, or any other unacceptable behavior.

\subsection{EVAlUation OF THE $\mathrm{UO}_{2}$ PINS}

The operating conditions for the $\mathrm{UO}_{2}$ pins in U0-1 are compared to the previously irradiated pins of similar design in Table 5-1. The pins in the previously irradiated tests have been irradiated to much higher exposures and burnups than planned for U0-1. The U0-1 power-to-flow is relatively high, but is enveloped by the $C-1$ pins. The conditions in the vo- 1 pins are actually not as severe as predicted by the power-to-flow ratio, since the relatively high power $\mathrm{UO}_{2}$ pins are surrounded by lower power pins (See Figure 3-1). Surrounding the high power pins with lower power pins has the effect of lowering the peak coolant temperature. The last column of Table 5-1 shows the peak coolant temperatures for the assembly. The U0-1 peak coolant temperature is 
relatively mild when compared to the other tests that have been irradiated in FFTF.

The major difference between the U0-1 test and the other tests is that the U0-1 test utilizes enriched uranium oxide fuel instead of mixed U-Pu oxide. The enriched $\mathrm{UO}_{2}$ will behave very similar to the mixed oxide. There will be only small differences in the material properties. The mixed oxide is approximately $70 \%$ uranium oxide. The mixed oxide has a lower melting point, and a slightly lower thermal conductivity. The margin to melting is therefore higher for the $\mathrm{UO}_{2}$ pins. The use of annular fuel will increase this margin. The nuclear properties are also slightly different. The energy release per fission and fission product distribution are slightly different. These differences are small, but they can affect the fission gas pressure at end of 1 ife.

In order to determine the effects of $\mathrm{UO}_{2}$ fuel versus the mixed oxide, fuel pin performance calculations were performed with the SIEX 3 code. 9 The SIEX3 code predicts the coolant, cladding, and fuel temperatures as well as calculating other fuel performance parameters such as cladding damage and swelling. SIEX3 has been used extensively to evaluate the steady state performance of tests in FFTF. An evaluation of the performance after 270 EFPD was made for this test for two cases: (1) a $42.9 \%$ enriched $\mathrm{UO}_{2}$ pin, and (2) a mixed oxide pin. The $\mathrm{UO}_{2}$ and mixed oxide pin dimensions and operating conditions were assumed to be exactly the same for this analysis. Conditions assumed for the test are shown in Table 5-2 and the results are shown in Table 5-3. The coolant and cladding temperatures are identical. The mixed oxide peak fuel temperatures are slightly higher. The fission gas pressure and the stress rupture damage fraction (SRDF) are slightly higher for the $\mathrm{UO}_{2}$ pin. A cladding breach would, however, not be expected for either type of pin at these low SRDFs. The results indicate that the conditions for the $\mathrm{UO}_{2}$ pins and mixed oxide are nearly identical. It is therefore appropriate to apply the data base for mixed oxide pins to the $\mathrm{UO}_{2}$ pins. Since mixed oxide pins have operated successfully at much higher powers and exposures, the $\mathrm{UO}_{2}$ pins are acceptable for steady-state irradiation.

\subsection{S-4 MIXED OXIDE PIN EVALUATION}

The S-4 pins will operate at a peak 1 inear power of approximately $10.74 \mathrm{~kW} / \mathrm{ft}$, which is considerably less than the $13.5 \mathrm{~kW} / \mathrm{ft}$ peak linear power assumed for the $\mathrm{UO}_{2}$ pins. Mixed oxide pins were shown to be acceptable at the $13.5 \mathrm{~kW} / \mathrm{ft}$ peak 1 inear power in Section 5.2. Similar pins have been run at higher powers for longer exposures, as discussed in Section 5.1. The S-4 pins are therefore acceptable for this test.

\subsection{DRIVER FUEL PINS}

The allowable lifetime of the driver pins is controlled by FFTF Technical Specification Figure 17.3.1.2-1. This figure is reproduced as Figure 5-1. Since this assembly is not a driver fuel assembly, the specification does not apply directly, but it is still an appropriate method for determining the lifetimes of these driver fuel pins. The allowable pin lifetime is given as a function of axial average linear fission power. The highest power driver fuel pin is expected to operate at a peak linear power of $9.70 \mathrm{~kW} / \mathrm{ft}$. The 
driver lifetime was computed assuming a beginning-of-life peak linear power of $10.25 \mathrm{~kW} / \mathrm{ft}$. A higher-than-predicted power was used in the lifetime evaluation, since the assembly power can vary if last minute core load changes are made. The driver fuel pin lifetime calculation was performed in the following steps.

1. The assembly flow is less than an inner row driver fuel assembly. The peak linear power was increased so that the power-to-flow was the same as a driver assembly with equivalent power. This type of correction is routinely applied to driver fuel assemblies, as discussed in the Technical Specification Bases.

2. The peak linear power was converted to axial average power by dividing by the axial peaking factor for this core position (1.21).

3. The axial average power was converted from deposited power to fission power by dividing by the fraction of power deposited in the pins $(0.936)$.

4. The allowable lifetime was computed from Figure 5-1.

The computed lifetime is 422 EFPD. Since the exposure limit for this test is only 270 EFPD, the driver fuel pin lifetime is acceptable.

The 3.1 driver fuel pins are vendor qualification pins and do not contain a gas tag. The lack of a gas tag will result in slightly lower fuel temperatures at beginning-of-life, since the presence of krypton or xenon lowers the thermal conductivity of the helium fill gas. The effect will be small, and is in the conservative direction. Each of the vendor qualification pin fabrication and storage histories is being examined to assure that there are no safety problems. Any nonconformances relative to the driver fuel specification will be addresed in the review of the TDD-II for the test, and the technical justification reviewed and approved prior to final approval to irradiate the test. 
WHC-SP-0549

Table 5-1. Experience with $\mathrm{D} 9 \mathrm{Cl}$ ad, 0.230 Inch Diameter Oxide Fuel

\begin{tabular}{|c|c|c|c|c|c|c|c|}
\hline TEST & $\begin{array}{l}\text { IRRA } \\
C Y \\
\text { STAR } \\
\end{array}$ & $\begin{array}{l}\text { ATION } \\
\text { ES } \\
\text { FINISH } \\
\end{array}$ & $\begin{array}{l}\text { BOL PEAK } \\
\text { LINEAR POWER } \\
\text { KW/FT } \\
\end{array}$ & $\begin{array}{c}\text { EOL* } \\
\text { EXPOSURE } \\
\text { EFPD } \\
\end{array}$ & $\begin{array}{l}\text { EOL* } \\
\text { BURNUP } \\
\text { MWD/KG } \\
\end{array}$ & $\begin{array}{l}\text { BOL POWER } \\
\text { TO FLOW } \\
\text { KW/FT/LB/HR } \\
\end{array}$ & $\begin{array}{c}\text { PEAK CLAD*** } \\
\text { TEMPERATURE } \\
{ }^{\circ} \mathrm{F} \\
\end{array}$ \\
\hline$D 9-1$ & 1 & 4 & 13.4 & 418 & 101 & $6.3 \times 10^{-5}$ & 1166 \\
\hline$D 9-2$ & 1 & 7 & 12.4 & 644 & 131 & $5.8 \times 10^{-5}$ & $<1166$ \\
\hline D9-3 & 1 & $10 B$ & 10.1 & 1448 & 187 & $6.0 \times 10^{-5}$ & $<1166$ \\
\hline D9-4 & 2 & 7 & 12.2 & 686 & 145 & $5.8 \times 10^{-5}$ & $<1166$ \\
\hline$C-1$ & 3 & 6 & 11.6 & 436 & 101 & $7.9 \times 10^{-5}$ & 1217 \\
\hline CRBR-5 & 3 & 6 & 12.5 & 436 & 106 & $6.6 \times 10^{-5}$ & 1157 \\
\hline U0-1 & $11 B$ & $12 \mathrm{~A}$ & 13.2 & 250 & 51 & $7.9 \times 10^{-5}$ & 1128 \\
\hline
\end{tabular}

* Exposures and Burnups were taken from the Reload Design Reports and reflect planned operation. Since the actual cycle lengths may have been slightly different, these numbers are approximate.

**Estimated temperatures from the Independent Safety Evaluations 
Table 5-2. Steady-State Analysis Assumptions

Peak Linear Power $-\mathrm{UO}_{2}$ Pins $(\mathrm{kW} / \mathrm{ft}$ )

Peak Linear Power - S-4 Pins (kW/ft)

11.5

Peak Linear Power - Driver Fuel Pins $(\mathrm{kW} / \mathrm{ft})$

10.25

Assembly Flow (1b/hr)

171,220

Peak Coolant Temperature $\left({ }^{\circ} \mathrm{F}\right)$

1128

End of Life Exposure (EFPD)

270

Power Decrease with Exposure (\%/270 EFPD)

BOL Cladding Thickness (inch)

0.014

Analysis Conditions 


\section{WHC-SP-0549}

Table 5-3. Comparison of $\mathrm{UO}_{2}$ and Mixed Oxide Steady State Results

\begin{tabular}{|c|c|c|c|c|}
\hline & $\begin{array}{l}\text { U02 PINS } \\
\text { BOL } \\
\end{array}$ & $\begin{array}{c}\text { MIXED } \\
\text { OXIDE PINS } \\
\text { BOL } \\
\end{array}$ & $\begin{array}{l}\mathrm{UO}_{2} \text { PINS } \\
\text { EOL }\end{array}$ & $\begin{array}{c}\text { MIXED } \\
\text { OXIDE PINS } \\
\text { EOL } \\
\end{array}$ \\
\hline Nominal Peak Linear Power $(\mathrm{kW} / \mathrm{ft})$ & 13.5 & 13.5 & 13.5 & 13.5 \\
\hline Peak Coolant Temperature $\left({ }^{\circ} \mathrm{F}\right)$ & 118 & 1181 & 1144 & 1144 \\
\hline Peak Cladding Temperature $\left({ }^{\circ} \mathrm{F}\right)$ & 1246 & 1246 & 1205 & 1205 \\
\hline Peak Fuel Temperature $\left({ }^{\circ} F\right)$ & 4788 & 4832 & 4153 & 4306 \\
\hline Fission Gas Pressure (psi) & 101 & 101 & 731 & 700 \\
\hline Cladding Diameter Increase (\%) & 0.0 & 0.0 & 0.27 & 0.26 \\
\hline Cladding Wastage (inch) & 0.0 & 0.0 & 0.0021 & 0.0021 \\
\hline Stress Rupture Damage Fraction & 0.0 & 0.0 & 0.064 & 0.057 \\
\hline
\end{tabular}




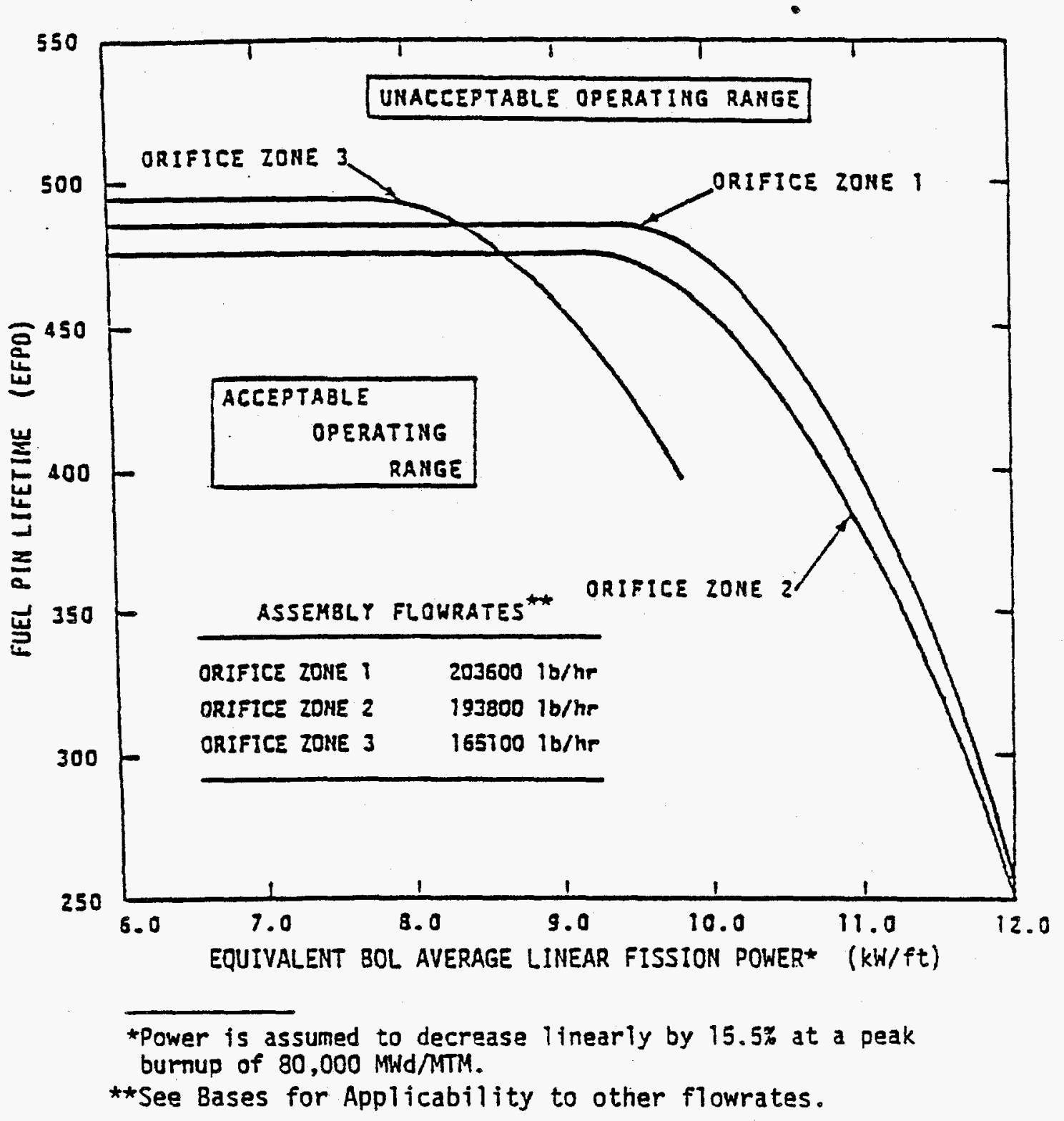

FIGURE 5-1. Steady-State Fuel Pin Lifetimes 
WHC-SP-0549

\subsection{TRANSIENT ANALYSES}

WHC-SP-0333 ${ }^{3}$ lists a number of design transients that are to be evaluated to determine the transient performance of experiments. The effects of these transients on tests sych as C-1, CRBR-5, and D9-1 have been evaluated in the ISES for these tests. (5-8) The tests were found to be acceptable. Since, as discussed in Section 5, these tests operated at higher powers and higher cladding temperatures than $00-1$, and the designs of these tests are similar to U0-1, the transient analyses for these tests envelopes the U0-1 test. The fact that some of the U0-1 fuel is enriched $\mathrm{UO}_{2}$ will not change this conclusion. The $\mathrm{UO}_{2}$ has a higher melting temperature and higher thermal conductivity than the mixed oxide, so the margin to fuel melting is higher. The annular fue will further increase the power-to-melt. Section 5.2 indicates that the $\mathrm{UO}_{2}$ pins had a slightly higher fission gas pressure than mixed oxide pins at the same exposure. The end-of-life exposures for the previously irradiated tests discussed in Section 5 are much higher than the planned exposure for the U0-1 test. The transient analyses for the previously irradiated tests were performed at much higher pin fission gas pressures than will occur in any of the U0-1 pins. The peak transient coolant temperatures would be well below boiling, and the probability of a cladding breach is low for this test. The test is therefore judged to be acceptable with respect to the design transients.

\subsection{FAILURE CONSEQUENCES}

Various failure modes have been evaluated for this test including the consequences of a cladding breach, misloading of the pins, and misloading of the test. These failure modes are discussed in Section $7.1,7.2$, and 7.3 , respectively.

\subsection{CONSEQUENCES OF A CLADDING BREACH}

The consequences of a cladding breach in the $\mathrm{UO}_{2}$ or S-4 pins would be the same as if a breach occurred in a standard driver fuel assembly. A fission gas signal would be noted and the test identified by the tag gas. A delayed neutron signal might occur (probably some time after the breach), and an unplanned shutdown might be required to remove the test from the reactor, but there would be no other safety impact. The impact of a cladding breach in the test driver pins would be the same except, since these pins do not contain a gas tag it might not be possible make a positive identification that the U0-1 test was the assembly with the breached pin. Removal of several tests might be required, and it is conceivable that more than one shutdown might be required to locate the assembly that released the fission gas. This mode of operation is undesirable from a plant operations impact, but is not unacceptable in terms of safety. A cladding breach in this test is unlikely because of the relatively mild conditions and the low exposure, so this risk has been judged to be acceptable. ${ }^{4}$ 
WHC-SP-0549

\subsection{MISLOADING OF THE PINS}

There would be no safety impact of misloading the pins within the assembly. The highest power pins are located near the center of the assembiy, which is very close to the hottest location. The $\mathrm{UO}_{2}$ or S-4 pins would operate at slightly higher powers if misloaded near the side of the assembly closest to the core centerline, but as discussed in Sections 5 and 6 , these pins are not operating close to any safety limits. The power gradient in Row 4 is not very steep, and the change in pin power due to misloading a pin would be a few percent at most. A misload of the pins would compromise obtaining data from the test, but would be benign in terms of safety.

\subsection{MISLOADING OF THE UO-1 ASSEMBLY INTO THE INCORRECT CORE LOCATION}

The test is designed to be irradiated in a Row 4 position and would operate at higher than design temperatures if accidentally placed in a more central position. However, the misloading of an assembly has a very low probability. There are a number of safeguards performed that would identify and correct such a misload. These safeguards have been effective in preventing an ascent to power with an incorrectly loaded assembly.

The worst-case misload would be to place the UQ-1 assembly in core center (Row 1). The fission rate data in WHC-SP-03333 indicates that the fission rates are approximately 15\% higher in Row 1 as compared to Position 2405. Locating the test in Row 1 instead of Row 4 would therefore result in approximately a $15 \%$ increase in the pin power. A $15 \%$ increase in power would not lead to sodium boiling, and in fact, the peak coolant temperature rise for the $\mathrm{C}-1$ assembly was over $15 \%$ higher than $00-1$ (See Table 5-1). The worstcase misload would not cause the test to operate at a power-to-flow that is unacceptable.

\subsection{HCDA ANALYSIS}

The U0-1 test would behave during the HCDA in a similar manner to a standard driver fuel assembly. The time at which pin failure occurred might be slightly different than would occur for a standard driver fuel assembly, but the U0-1 assembly would have no significant effect on the HCDA consequences.

\subsection{STRUCTURAL AND SEISMIC ANALYSIS}

The v0-1 structural and seismic performance would be identical to a standard driver fuel assembly, since there are no significant differences in terms of the structural or seismic design of the test.

\subsection{CRITICALITY AND TEST HANDLING CONSIDERATIONS}

The U0-1 test has been reviewed for criticality safety and has been placed on the list of approved assemblies as an assembly no more reactive than a driver fuel assembly. The criticality limits used for handling the standard driver fuel assemblies are appropriate.

There are no special handling considerations for this test. Reference driver handling limits are appropriate, since there are no failure mechanisms, such 
as eutectic penetration, that would require special limits. The decay heat limits for refueling specified in Technical Specification 17.3.7.2 for CLEM, IDS, IEM Ce11, TACS, CCS, BLTC and FSF apply.

\subsection{REFERENCES}

1. D. B. Graves, Test Design Description Volume 1B for the Enriched Uranium Oxide Tests UO-1 and U0-2, WHC-SD-TDD-006, September 15, 1989.

2. A. E. Bridges, Test Design Description Volume 1A for the Enriched Uranium Oxide Test U0-1 (HF226), WHC-SD-TDD-008, Rev A, September 1989.

3. D. C. Corrigan, Users' Guide for the Irradiation of Experiments in the Fast Test Reactor, WHC-SP-0333, September 1988.

4. Memo, D. C. Corrigan to E. J. Shen, "Approval of Waiver for WHC-SP0333 Gas Tagging Requirements for the UO-1 Test," August 23, 1989.

5. F. J. Heard, Independent Safety Evaluation for the Improved Oxide Fuel Test Series D9-1, -2 and, -3 (HF092, 093 AND 094) HEDL-TC-2096, November, 1981.

6. F. J. Heard, Independent Safety Evaluation for the CRBRP Prototype Test Assembly CRBR-5 (WF121), HEDL-TC-2306, February 1983.

7. F. J. Heard, Independent Safety Evaluation for the Improved Oxide Fuel Test Series D9-4 (HF122), HEDL-TC-2205, June 1982.

8. J. C. Van Keuren, Independent Safety Evaluation of the C-1 Test (HF127), HEDL-TC-2349, March 1983.

9. R. B. Baker and D. R. Wilson, SIEX3 - A Correlated Computer Code for the Prediction of Fast Reactor Mixed Oxide Fuel and Blanket Performance, HEDL TME-85-18, January 1985. 


\section{Number of Copies}

ONSITE

3

U. S. Department of Energy -

Richland Operations Office

J. G. Hennig

A6-55

A. W. Kellog (w/o attachment) A6-53

V. C. Wahler

A6 -53

25

Westinghouse Hanford Company

R. A. Bennett

N2 -32

A. E. Bridges

L5 -05

L. R. Campbell

N2 -32

D. C. Deere

J. 0. Dittmer

N1 -31

J. L. Ethridge

R. C. Knight

$44-30$

L5- 01

J. L. Marshall

L6-37

T. B. McCall

$\mathrm{N} 2-02$

L. D. Muhlestein

$\mathrm{HO}-33$

A. L. Pitner

N1 -28

J. N. Nansen

L5-05

J. L. Rathbun

L6-35

N1 -71

R. D. Redekopp

N2-33

A. R. Schade

R3-04

E. J. Shen

D. D. Stepnewski

J. C. Van Keuren (3)

Central Files (2)

L5- 05

N1-31

N1-31

L8-04

Publication Services(3)

A2-24

\section{DO NOT MICROFILM \\ THIS PAGE}

Distr-1 